\title{
UM OLHAR SOBRE A DOCÊNCIA DO PROFESSOR NÃO LICENCIADO NA EDUCAÇÃO PROFISSIONAL E TECNOLÓGICA: Uma Pesquisa Bibliográfica
}

\author{
Ana Paula da Costa Alves ${ }^{1}$ \\ Vantoir Roberto Brancher ${ }^{2}$
}

\begin{abstract}
RESUMO
Este estudo propõe-se a apresentar o Estado do Conhecimento que analisou artigos acerca da formação docente de professores não licenciados atuantes na Educação Básica Profissional Técnica Tecnológica (EBPTT). O trabalho mapeou por meio da plataforma SciELO (Scientific Electronic Library On-line) artigos que discutissem a temática em destaque. Para tanto, foi delimitado o período de 2013 a 2018, na busca por produções, tendo em vista o descritor "Educação Profissional e Tecnológica" (EPT). A partir disso, os artigos foram reunidos de acordo com as seguintes categorias: Identidade docente, Professor na EPT, Professor Bacharel/Tecnólogo e Formação Pedagógica. A busca resultou na identificação de nove artigos, que apontaram alguns eixos de discussão da docência na EPT, inclusive os pontos que necessitam de maior aprofundamento, como a formação do professor não licenciado. Foram acrescentados seis artigos, considerando o mesmo recorte temporal, em virtude da relevante contribuição e alcance acerca da formação docente para EPT. Procuramos, portanto, esclarecer aspectos pouco ou não suscitados pelas pesquisas em educação, sobretudo, na área da docência na EPT.
\end{abstract}

Palavras-chave: Docência. Educação Profissional e Tecnológica. Professor não licenciado.

\section{A LOOK ABOUT THE TEACHING OF THE UNLICENSED TEACHER IN PROFESSIONAL AND TECHNOLOGICAL EDUCATION: A BIBLIOGRAPHIC RESEARCH}

\begin{abstract}
This study proposes to present the Knowledge State that analyzed articles about the teacher training of unlicensed teachers active in EBPTT ("Educação Básica Profissional Técnica Tecnológica" - Basic Professional Education Technological Technique). The study mapped through the platform SciELO (Scientific Electronic Library On-line), articles that discussed the theme highlighted. To this end, was delimited the period 2013 a 2018, in the search for productions, in view of the descriptor "Professional and Technological Education" (EPT - "Educação Profissional e Tecnológica"). From this, the articles were gathered according to the following categories: Teacher Identity, Teacher at EPT, Bachelor/technologist Teacher and Pedagogical Training. The research resulted in nine articles, which under different views pointed out the main discussion axes of the teachers teaching unlicensed in the EPT, including the points that need further deepening. Six articles were added, considering the same temporal return, due to the relevant contribution and scope on teacher training for EPT.Therefore, we try to clarify aspects little raised, or no raised, by the researches in Education, especially in the field of teaching of the EPT.
\end{abstract}

Keywords: Teaching. Professional and technological education. Unlicensed teacher.

Recebido em: 7/3/2020

Aceito em: $30 / 3 / 2020$

\footnotetext{
1 Graduação em Pedagogia pela Universidade Federal do Piauí (2011). Graduação em Letras/Português pela Universidade Estadual do Piauí (2012). Mestranda do curso de Mestrado Profissional em Educação Profissional e Tecnológica (Instituto Federal Farroupilha, Campus Jaguari). http://lattes.cnpq.br/8336560846895140. https://orcid.org/0000-0002-7798-3872. anapaulaalves@live.com.

2 Graduação em Pedagogia (1999), Especialização em Educação Especial, AH/SD (2008), Mestrado em Educação (2006) e Doutorado em Educação (2013) pela Universidade Federal de Santa Maria (UFSM). Professor efetivo do Instituto Federal de Educação Ciência e Tecnologia Farroupilha, atuando em cursos de Licenciatura e Pós-Graduação. Tem realizado estudos e pesquisas em Formação de Professores, Gênero, Diversidade e Inclusão. Coordena o Grupo de Estudos e Pesquisas em Formação Inicial e Continuada de Professores - Magma: https://magma872. webnode.com. http://lattes.cnpq.br/3260077562370842. https://orcid.org/0000-0003-2829-7320. vantoir.brancher@iffarroupilha.edu.br.
} 
Este estudo é resultado da necessidade de mapear produções científicas que discutam a formação docente para professores não licenciados na Educação Básica Profissional Técnica Tecnológica (EBPTT), assim resultando na construção do Estado do Conhecimento da temática em realce. É necessário reconhecer que o Estado do Conhecimento é uma ferramenta indispensável no desenvolvimento do trabalho científico, pois auxilia na sistematização das problemáticas levantadas em torno do objeto a ser analisado.

Dessa forma, Morosini e Fernandes (2014, p. 158) entendem que: “O Estado de Conhecimento possibilita uma visão ampla e atual dos movimentos da pesquisa ligados ao objeto da investigação que pretendemos desenvolver. É, portanto, um estudo basilar para futuros passos dentro da pesquisa pretendida". Conhecer a abrangência das pesquisas em uma determinada área possibilita, sobretudo, explorar resultados sob visões diferentes e, por consequência, enriquecer o processo de investigação.

Buscou-se compilar trabalhos vinculados à esfera EPT e que tratam da formação docente com publicação no portal Scientific Electronic Library On-line (SciELO), no período de 2013 a 2018. Considerando o desenvolvimento dos IFs na cena educacional brasileira, acreditamos que ao destacar tal espaço temporal nos foi possível evidenciar maior produtividade e maturidade dos trabalhos acerca da docência na EPT, principalmente, no que diz respeito ao professor não licenciado (bacharéis e tecnólogos).

Nesse sentido, consideramos analisar trabalhos no marco temporal mencionado, em virtude da mudança que tornou os Centros Federais de Educação Tecnológica (Cefets) em Institutos Federais. ${ }^{3}$ Logo, cinco anos depois (2013), a lógica e percepção da atividade educacional e, por consequência, do trabalho docente nessas instituições se modificou, demandando pesquisas e discussões.

Em virtude da ampliação do número de Institutos Federais observou-se um aumento no número de bacharéis e tecnólogos atuando como professores:

Acontece que tanto a educação chamada profissional como os cursos superiores formam profissionais que são formados por profissionais que atuam como professores, embora, na maioria das vezes, não tenham formação específica para esse fim (MOURA, 2008, p. 32).

Este artigo pretende discutir a constituição da identidade docente nesses profissionais, observando como a produção científica atual tem discutido tal realidade: a docência dos bacharéis e tecnólogos nos Institutos Federais. Nesse ponto, é necessário observar que estes professores não atuam apenas na Educação Profissional Tecnológica (EPT), mas também em outras modalidades educacionais.

\section{MAPEAMENTO DAS PRODUÇÕES}

A partir das congruências e divergências encontradas durante a análise, nos foi proporcionado olhar a formação do professor na EPT sob diversos prismas. O estudo acerca da formação docente na e para EPT apresentou-se como uma discussão necessária e essencial ao desenvolvimento de práticas de ensino que estejam adequadas ao contexto dessa modalidade de ensino.

Lei no 11.892, de 29 de dezembro de 2008 (BRASIL, 2016). 
Procuramos agrupar os artigos a partir de um descritor principal e tematicamente amplo, "Educação Profissional e Tecnológica", para inserir os filtros necessários à seleção dos artigos analisados nesse escrito. Foram aplicados os filtros do próprio ambiente: quanto ao idioma (Português), fonte (artigos), ano de publicação (2013-2018). Também foi possível situar os estudos por área de concentração (Educação e Pesquisas Educacionais).

À luz da teoria de análise de conteúdo estudamos os artigos a partir das seguintes categorias: identidade docente, professor na EPT, professor bacharel/tecnólogo, formação pedagógica. Segundo Bardin (1977, p. 117): “categorização é uma operação de classificação de elementos constitutivos de um conjunto, por diferenciação e, seguidamente, por reagrupamento segundo o género (analogia), com os critérios previamente definidos". Assim, as categorias referendam o processo de discussão apontando quais e com que profundidade os trabalhos reunidos exploram a temática em evidência.

É necessário observar que os professores bacharéis ou tecnólogos não atuam como docentes apenas na EPT, mas também nas universidades. Convém, ainda, refletir sobre a necessidade de cursos de formação pedagógica que alcancem este público. Desse modo, a definição das categorias visa a reunir o maior número de trabalhos que explorem a constituição da docência do professor bacharel/tecnólogo, como destaca o quadro a seguir:

Quadro 1 - Panorama das produções relacionadas às expressões temáticas

\begin{tabular}{|l|c|}
\hline \multicolumn{1}{|c|}{ Expressões temáticas } & No de artigos selecionados \\
\hline Identidade docente & 2 \\
\hline Professor Bacharel/ Tecnólogo & 4 \\
\hline Docência na EPT & 9 \\
\hline Formação pedagógica & 1 \\
\hline
\end{tabular}

Fonte: A autora.

No quadro a seguir reunimos os artigos encontrados pela busca na plataforma, situando quanto ao ano de publicação e resumo do conteúdo de cada trabalho. Faz-se oportuno mencionar que alguns artigos foram excluídos, pois durante a análise pouco ou nada convergiam com a temática em estudo. Ou seja, apesar de articular aspectos da docência na EPT, eram pouco aprofundados na questão dos professores bacharéis/ tecnólogos. 
Quadro 2 - Seleção das publicações relacionadas à EPT ${ }^{4}$

\begin{tabular}{|c|c|c|c|c|}
\hline № & 岁迹 & TÍTULO & 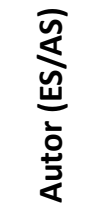 & SÍNTESE DO TRABALHO \\
\hline 1 & \multirow{2}{*}{$\underset{\sim}{\stackrel{\nabla}{D}}$} & $\begin{array}{l}\text { Formação do docente da Educação } \\
\text { Profissional e Tecnológica no Brasil: um } \\
\text { diálogo com as faculdades de Educação } \\
\text { e o curso de Pedagogia }\end{array}$ & 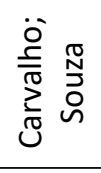 & $\begin{array}{l}\text { Apontam para necessidade da } \\
\text { formação de professores considerar } \\
\text { a natureza do trabalho docente na } \\
\text { EPT. }\end{array}$ \\
\hline 2 & & $\begin{array}{l}\text { A cultura profissional dos grupos de } \\
\text { pesquisa nos Institutos Federais: uma } \\
\text { comunidade de práticas? }\end{array}$ & 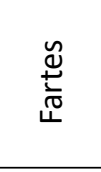 & $\begin{array}{l}\text { Grupos de pesquisa e a produção } \\
\text { do conhecimento científico como } \\
\text { base para o processo de formação } \\
\text { docente. }\end{array}$ \\
\hline 3 & $\stackrel{\text { 늄 }}{\stackrel{2}{\sim}}$ & $\begin{array}{l}\text { Concepção de Biossegurança de docentes } \\
\text { do Ensino Técnico de Enfermagem em } \\
\text { um estado do sul do Brasil }\end{array}$ & 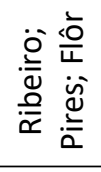 & $\begin{array}{l}\text { A relevância do desenvolvimento } \\
\text { de abordagem pedagógica acerca } \\
\text { do conceito de Biossegurança em } \\
\text { cursos técnicos dos IFs. }\end{array}$ \\
\hline 4 & $\begin{array}{l}\stackrel{6}{\sim} \\
\stackrel{\sim}{\sim}\end{array}$ & $\begin{array}{l}\text { A relevância do processo de autoavaliação } \\
\text { institucional da Universidade Tecnológica } \\
\text { para a configuração do bom professor }\end{array}$ & 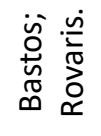 & $\begin{array}{l}\text { A autoavaliação como processo } \\
\text { de construção da figura do "bom } \\
\text { professor". }\end{array}$ \\
\hline 5 & \multirow{3}{*}{ 궁 } & $\begin{array}{l}\text { Percurso formativo de engenheiros } \\
\text { professores da Educação Profissional e } \\
\text { Tecnológica }\end{array}$ & స̃ & $\begin{array}{l}\text { Analisa a trajetória formativa de } \\
\text { engenheiros que se tornaram } \\
\text { docentes na EPT. }\end{array}$ \\
\hline 6 & & $\begin{array}{l}\text { A formação profissional nos cursos de } \\
\text { licenciatura e o exercício do magistério na } \\
\text { educação básica: intenções, realizações } \\
\text { e ambiguidades }\end{array}$ & 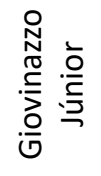 & $\begin{array}{l}\text { Discute os modelos de formação de } \\
\text { professores no contexto brasileiro, } \\
\text { o que reflete também sobre a EPT. }\end{array}$ \\
\hline 7 & & $\begin{array}{l}\text { Evolução do perfil didático-pedagógico } \\
\text { do professor-engenheiro }\end{array}$ & 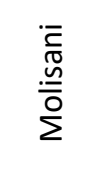 & $\begin{array}{l}\text { Reflete sobre a formação docente } \\
\text { tendo por referência o dualismo } \\
\text { entre a formação específica e o } \\
\text { conhecimento pedagógico. }\end{array}$ \\
\hline 8 & \multirow{2}{*}{$\stackrel{\infty}{\stackrel{\sim}{\circ}}$} & $\begin{array}{l}\text { Mediação entre a escola e o novo mundo } \\
\text { trabalho na formação de técnicos de } \\
\text { nível médio }\end{array}$ & 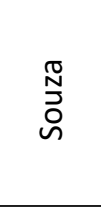 & $\begin{array}{l}\text { Reflete acerca da reprodução } \\
\text { de uma lógica mercadológica na } \\
\text { formação técnica ofertada pelos } \\
\text { IFs, ressaltando a ação docente } \\
\text { nesse panorama. }\end{array}$ \\
\hline 9 & & $\begin{array}{l}\text { O trabalho docente nos Institutos } \\
\text { Federais no contexto da Expansão da } \\
\text { Educação Superior }\end{array}$ & $\sum_{\substack{0+\infty \\
i}}^{\frac{0}{0}}$ & $\begin{array}{l}\text { Problematização da oferta em } \\
\text { larga escala dos cursos de ensino } \\
\text { superior pelos IFs, apontando a } \\
\text { sobrecarga do trabalho docente e } \\
\text { ausência de espaços de formação. }\end{array}$ \\
\hline
\end{tabular}

Fonte: A autora.

\footnotetext{
${ }^{4}$ Os artigos, referentes ao ano de 2013, selecionados a partir dos filtros de busca do site SciELO não foram incluídos, uma vez que em análise preliminar discutiam a EPT de modo amplo, não apresentando contribuições sobre a temática da docência na EPT.
} 
Logo, a incursão bibliográfica mostrou-se frutífera por nos permitir lançar novos olhares sobre a identidade docente, os trajetos de formação do professor dos IFs. A seguir passamos a analisar os artigos conforme o período de sua publicação.

Quadro 3 - Publicações analisadas (2014)

\begin{tabular}{|l|c|c|c|c|c|}
\hline \multicolumn{1}{|c|}{ Artigos } & Autores & $\begin{array}{c}\text { Descritores } \\
\text { Identidade } \\
\text { docente }\end{array}$ & $\begin{array}{c}\text { Professor } \\
\text { Bacharel/ } \\
\text { Tecnólogo }\end{array}$ & $\begin{array}{c}\text { Docência } \\
\text { na EPT }\end{array}$ & $\begin{array}{c}\text { Formação } \\
\text { pedagógica }\end{array}$ \\
\hline $\begin{array}{l}\text { Formação do docente da Educação } \\
\text { Profissional e Tecnológica no Brasil: } \\
\text { um diálogo com as faculdades de } \\
\text { Educação e o curso de Pedagogia }\end{array}$ & $\begin{array}{c}\text { Carvalho; } \\
\text { Souza }\end{array}$ & - & - & $x$ & $x$ \\
\hline $\begin{array}{l}\text { A cultura profissional dos grupos } \\
\text { de pesquisa nos Institutos Federais: } \\
\text { uma comunidade de práticas? }\end{array}$ & Fartes & $x$ & - & $x$ & \\
\hline
\end{tabular}

Fonte: A autora.

Quanto aos artigos de 2014, destacamos o estudo "Formação do docente da Educação Profissional e Tecnológica no Brasil: um diálogo com as faculdades de Educação e o curso de Pedagogia", cujos autores introduzem a discussão com as seguintes indagações:

//5há especificidades na formação do docente da EPT? Como e onde os professores da EPT adquirem os saberes da docência? Quais são os saberes mobilizados pelos docentes em sua prática profissional? Que modelo(s) de formação responderia $(\mathrm{m})$ adequadamente a essas questões? A cultura profissional dos grupos de pesquisa nos Institutos Federais: uma comunidade de práticas? (CARVALHO; SOUZA, 2014, p. 884).

Os autores discutem sobre a formação do docente não licenciado e aquele oriundo de curso de Licenciatura ou do curso de Pedagogia. As indagações nos remetem ao problematizado, neste artigo, no que se refere à formação pedagógica para bacharéis/ tecnólogos que vivenciam a docência.

Em se tratando de EPT, no entanto, é observado um público diverso de indivíduos que atuam na docência: bacharéis, tecnólogos, além dos licenciados, o que diversifica as ações e o saber docente. Os autores também apresentam em seu estudo o número de 190 professores que não receberam formação pedagógica antes de atuarem como docentes, tendo a maioria (134 professores) considerado um problema a ausência dos conhecimentos relativos ao saber pedagógico.

A EPT, a exemplo de outras modalidades de ensino, vivencia um quadro no qual professores atuam sem formação pedagógica, apontando assim não apenas para uma demanda institucional por qualificação, mas requisitando responder a uma relevante questão que diz respeito ao ensino e, também, à identidade deste professor.

A marca gráfica sinaliza que a citação pertence ao artigo que compõe o Estado do Conhecimento, portanto que foram reunidos a partir do site SciELO ou que integra os estudos acrescentados para análise neste trabalho. 
Por consequência, o estudo de Carvalho e Souza (2014) aponta para a necessidade de refletir sobre a importância da formação de professores, principalmente no caso dos não licenciados. Nesse caso, é necessário observar que as vivências e características identitárias dos docentes são diversas e se modificam ao longo da vida.

Ainda, no período de 2014, constatamos o trabalho "A cultura profissional dos grupos de pesquisa nos Institutos Federais: uma comunidade de práticas?", de Fartes. O estudo buscou compreender o modo como ocorrem os grupos de pesquisa em um IF na Região Nordeste, caracterizando-se como um estudo de caso que utilizou a análise documental, entrevistas semiestruturadas e cadernos de campo.

O modo como se articulam os conhecimentos e saberes profissionais imprime diferentes formas de representação docente na esfera pedagógica e institucional dos IFs. As transformações pela qual a EPT passou ao longo de sua história revelam uma instituição e docentes preocupados em formar o cidadão e trabalhador, ao mesmo tempo em que são incisivamente pressionados pela lógica do mercado.

Outra questão realçada pela autora diz respeito à identidade docente como em permanente processo de constituição. Sobre isso, ao comentar a fragmentação da identidade na pós-modernidade, Hall (2006) comenta que não somos estanques, portanto somos resultado das várias identidades constituídas ao longo da vida. $O$ estudo preocupa-se com o desenvolvimento de uma visão profissional baseada nas múltiplas subjetividades que se reúnem em grupos de pesquisa.

Dessa forma, a condução de um olhar acerca dos grupos de pesquisa fundamentou-se no fato de serem o locus da vivência formativa:

[...] percebe-se uma nova sensibilidade nos pesquisadores em relação à educação enquanto processo social e cultural, com significados que se fazem públicos e compartilhados, mas cujo sentido se cria nas relações que permeiam suas práticas, seja em nível de sistemas, seja em nível das escolas, salas de aula, dos alunos, professores, pais, etc. (GATTI, 2006, p. 33).

A pesquisa por intermédio do trabalho colaborativo oportuniza desvelar identidades, reunir saberes que não se limitam aos professores, coordenadores, mas se estende às realidades estudadas, bem como aos alunos que experienciam o conhecimento na prática. Na visão de Oliveira (2009, p. 108): “[...], o grupo é espaço de resistência, onde o cultivo do trabalho e da reflexão compartilhada contraria a lógica individualista e competitiva, tão presente em nossas instituições acadêmicas". O grupo de pesquisa emerge como a oportunidade de dividir e (re)criar perspectivas das experiências de formação de seus participantes.

O artigo analisado, portanto, contribuiu de forma significativa ao empreender um olhar sobre o papel docente, afirmando a importância das diferentes identidades que se mobilizam na atividade de pesquisa. Dessa forma, aponta para a vivência do trabalho investigativo como algo construído de forma plural, na diversidade de saberes e fazeres. 
Quadro 4 - Publicações analisadas (2015)

\begin{tabular}{|l|c|c|c|c|c|}
\hline \multicolumn{2}{|c|}{2015} & \multicolumn{3}{c|}{ Descritores } \\
\hline \multicolumn{1}{|c|}{ Artigos } & Autores & $\begin{array}{c}\text { Identidade } \\
\text { docente }\end{array}$ & $\begin{array}{c}\text { Professor } \\
\text { Bacharel/ } \\
\text { Tecnólogo }\end{array}$ & $\begin{array}{c}\text { Docência } \\
\text { na EPT }\end{array}$ & $\begin{array}{c}\text { Formação } \\
\text { pedagógica }\end{array}$ \\
\hline $\begin{array}{l}\text { Concepção de Biossegurança de } \\
\text { docentes do Ensino Técnico de } \\
\text { Enfermagem em um Estado do Sul } \\
\text { do Brasil }\end{array}$ & $\begin{array}{c}\text { Ribeiro; } \\
\text { Pires; Flôr }\end{array}$ & - & $x$ & $x$ & \\
\hline
\end{tabular}

Fonte: A autora.

No recorte temporal de 2015 salientamos o trabalho "Concepção de biossegurança de docentes do Ensino Técnico de Enfermagem em um Estado do Sul do Brasil", das autoras Ribeiro, Pires e Flôr. Estas associam a construção do conceito de biossegurança na formação profissional de seu aluno por meio das ações/visão docente durante o ensino.

O artigo é consequência de uma pesquisa exploratória descritiva de abordagem qualitativa. Tem por objetivo identificar as concepções de biossegurança de docentes do Ensino Técnico de Enfermagem que atuam em instituições vinculadas à Rede Federal de Educação Profissional e Tecnológica.

Assim, constatam que os docentes mobilizam sua ação para a formação integral do aluno, ultrapassando uma visão meramente técnica: “[...] a análise de concepções e práticas na formação docente não pode ocorrer sem considerar o contexto social e histórico em que essas concepções e práticas foram produzidas, bem como as condições efetivas em que os professores desenvolvem seu trabalho" (GATTI et al., 2019, p. 180). Ou seja, o(a) docente encarrega-se de transpor o conhecimento formal acerca do conceito de biossegurança.

Além disso, é possível, que os professores entrevistados (enfermeiros, portanto bacharéis) não tenham participado de um curso de formação pedagógica (o estudo não esclarece quanto a esse aspecto). Há, contudo, vários indícios que demonstram como o professor mobiliza seu saber e fazer docente, a citar: a conversa sobre a realidade dos alunos, a busca por ir além das normas técnicas, experienciar de forma prática os conceitos discutidos, entre outros.

Quadro 5 - Publicações analisadas (2016)

\begin{tabular}{|c|c|c|c|c|c|}
\hline \multicolumn{2}{|l|}{2016} & \multicolumn{4}{|c|}{ Descritores } \\
\hline Artigos & Autores & $\begin{array}{l}\text { Identidade } \\
\text { docente }\end{array}$ & $\begin{array}{l}\text { Professor } \\
\text { Bacharel/ } \\
\text { Tecnólogo }\end{array}$ & $\begin{array}{l}\text { Docência } \\
\text { na EPT }\end{array}$ & $\begin{array}{l}\text { Formação } \\
\text { pedagógica }\end{array}$ \\
\hline $\begin{array}{llr}\text { A relevância do processo de } & \text { do } \\
\text { autoavaliação institucional da } \\
\text { Universidade Tecnológica para a } \\
\text { configuração do bom professor }\end{array}$ & $\begin{array}{l}\text { Bastos; } \\
\text { Rovaris }\end{array}$ & - & $x$ & $x$ & - \\
\hline
\end{tabular}

Fonte: A autora. 
Na sequência analisamos o trabalho "A relevância do processo de autoavaliação institucional da Universidade Tecnológica para a configuração do bom professor", de autoria de Bastos e Rovaris (2016). O artigo apresenta os resultados da autoavaliação institucional de uma Universidade Tecnológica, enfatizando a visão dos alunos. Desse modo, busca construir o perfil do "bom professor", tendo por consequência reflexos positivos sobre a prática docente e a ação dos gestores da instituição.

O trabalho caracteriza-se como uma pesquisa de cunho bibliográfico, uma vez que analisou o relatório do processo de Autoavaliação Institucional da Universidade Tecnológica Federal do Paraná (UTFPR), campus Medianeira, nos anos 2009, 2010 e 2011. A partir disso, definiu três perfis de docentes que participariam do estudo: aqueles cujas notas recebidas durante a avaliação situaram-se entre 9 e 10, os professores bacharéis e os professores que integram o quadro docente da Universidade Tecnológica com três anos ou mais de trabalho na instituição.

Foi analisado o posicionamento dos alunos da UTFPR quanto à forma de avaliação na instituição, que a entendem como tradicional e classificatória. A avaliação, nesse sentido, evidencia a necessidade de superar a padronização dos alunos, segundo Candau (2014, p. 37): "Conceber a dinâmica escolar nesta perspectiva supõe repensar seus diferentes componentes e romper com a tendência homogeneizadora e padronizadora que impregna suas práticas". Logo, foi ouvindo docentes e alunos que o perfil do "bom professor" naquele espaço foi sendo definido.

A partir da visão dos alunos, o corpo docente pode compreender que o ensino necessita se adaptar às singularidades de cada sala de aula, além de que a promoção do aluno requer considerar o seu desempenho em diversas situações, não se limitando a um teste/prova.

No trabalho foi constatado que a avaliação institucional é elemento condutor, ao que os autores classificam como a figura do "bom professor", que se formatou, principalmente, pelo feedback dos alunos. Nessa lógica, Cunha (1992, p. 155) analisa: “[...], o conceito de BOM PROFESSOR é valorativo, com referência a um tempo e a um lugar. Como tal é também ideológico, isto é, representa a ideia que socialmente é construída sobre o professor".

Assim, o estudo demonstrou-se exitoso por proporcionar uma gama de informações necessárias ao planejamento de políticas e práticas de formação continuada, bem como o assessoramento às já desenvolvidas pela UTFPR. Dessa forma, o trabalho sugere que $o$ ato de avaliar, assim como tantos outros implicados na vivência como professor, apontam para particularidades da formação docente, inclusive no que se refere aos bacharéis e tecnólogos. 
Quadro 6 - Publicações analisadas (2017)

\begin{tabular}{|c|c|c|c|c|c|}
\hline \multicolumn{2}{|l|}{2017} & \multicolumn{4}{|c|}{ Descritores } \\
\hline Artigos & Autores & $\begin{array}{l}\text { Identidade } \\
\text { docente }\end{array}$ & $\begin{array}{l}\text { Professor } \\
\text { Bacharel/ } \\
\text { Tecnólogo }\end{array}$ & $\begin{array}{l}\text { Docência } \\
\text { na EPT }\end{array}$ & $\begin{array}{l}\text { Formação } \\
\text { pedagógica }\end{array}$ \\
\hline $\begin{array}{l}\text { Percurso formativo de engenheiros } \\
\text { professores da Educação Profissional e } \\
\text { Tecnológica }\end{array}$ & Souza & $x$ & $x$ & $x$ & - \\
\hline $\begin{array}{l}\text { A formação profissional nos cursos de } \\
\text { licenciatura e o exercício do magistério } \\
\text { na educação básica: intenções, } \\
\text { realizações e ambiguidades }\end{array}$ & $\begin{array}{l}\text { Giovinazzo } \\
\text { Júnior }\end{array}$ & - & - & $x$ & - \\
\hline $\begin{array}{l}\text { Evolução do perfil didático-pedagógico } \\
\text { do professor-engenheiro }\end{array}$ & Molisani & - & $x$ & $\mathrm{x}$ & - \\
\hline
\end{tabular}

Fonte: A autora.

No período de 2017 selecionamos o estudo "Percurso formativo de engenheiros professores da Educação Profissional e Tecnológica", de Souza. O artigo apresenta um olhar sobre o trajeto profissional e pessoal de engenheiros que se tornaram professores em uma instituição de Educação Profissional e Tecnológica (EPT).

O trabalho aponta para a inserção de um expressivo volume de profissionais, cuja formação inicial se dá pela Engenharia, na EPT, dada a ampliação dos Institutos Federais nos últimos anos. A investigação foi realizada no Instituto Federal de Educação, Ciência e Tecnologia do Rio Grande do Norte (IFRN), Campus Mossoró, e teve por objetivo compreender o significado que os engenheiros professores atribuem às suas experiências na docência.

Em relação aos colaboradores da pesquisa foram entrevistados cinco professores, tendo por critério o mínimo de três anos de atividade docente. São egressos dos cursos de Engenharia Civil (três professores), Engenharia de Materiais (um professor) e Engenharia da Computação (um professor). No tocante à titulação dos professores colaboradores do estudo, um é doutor, dois são mestres e dois são especialistas. Apenas um docente tem Pós-Graduação na área de educação (Especialização).

Dada a formação inicial dos professores observa-se como a identidade destes se reconfigura, principalmente, por vivenciarem a docência. Nessa visão, Josso (2004, p. 42) entende que: “[...], o processo de formação acentua o inventário dos recursos experienciais acumulados e das transformações identitárias". O trabalho em educação atribui novo significado à formação como engenheiros que se ressignifica no fazer docente na EPT.

Quanto às justificativas ao exercício docência, alguns professores relatam o "dom" para ensinar. Segundo Souza (2017, p. 68), os sujeitos entrevistados entendiam que: // "[...], algumas pessoas têm a capacidade especial inata de lecionar, de doar ou passar conhecimentos". Nesse caso, afirmam que ensinavam seus pares quando na idade escolar, e que, por isso, identificaram-se como professores. 
Essa ideia excluiu da docência sua constituição como profissão, assim, afirma Roldão (2007, p. 101) que: "Torna-se saber profissional docente quando e se o professor o recria mediante um processo mobilizador e transformativo em cada acto pedagógico, contextual, prático e singular". A referida autora alerta que a docência reúne saberes que lhe são peculiares, porém ressignificados pelo tipo de formação e experiência como professor que cada indivíduo teve.

Os engenheiros professores, portanto, assim como toda categoria profissional, possuem uma gama de saberes que são resultado da singularidade da sua trajetória pessoal e profissional. Enfim, o estudo mostrou-se alinhado à nossa investigação, uma vez que relacionou professores cuja formação inicial decorre do Bacharelado e que vivenciam a docência na EPT.

Ainda no ano de 2017 destacamos o trabalho "A formação profissional nos cursos de licenciatura e o exercício do magistério na educação básica: intenções, realizações e ambiguidades", de autoria de Giovinazzo Júnior. O estudo busca compreender o modelo de formação docente previsto em documentos oficiais, assim como sua relação com as principais tendências relacionadas ao desenvolvimento da docência.

O autor discute a Resolução CNE/CP no 1, de 15/05/2006, que define as Diretrizes Curriculares Nacionais para o Curso de Graduação em Pedagogia, e o Parecer CNE/CP no 2, de 9/6/2015, que explicita as Diretrizes Curriculares Nacionais para a Formação Inicial e Continuada dos Profissionais do Magistério da Educação Básica.

A pesquisa considera a complexidade do fenômeno educativo, situando o professor como figura responsável por elencar e discutir desde os aspectos político-sociais aos fatos da vida cotidiana, entre outros. Dessa forma, enfatiza o modo como o professor desenvolve suas habilidades/competências na realidade em que está inserido, referendando assim a necessidade de refletir sobre sua formação.

Assim, o artigo destaca que as variáveis que contornam o perfil do egresso da Licenciatura em Pedagogia (seu foco de estudo) apontam para um indivíduo cuja formação é multifacetada. Logo, depreende-se que apesar da complexidade que envolve a formação do pedagogo, as diretrizes oficiais ainda sinalizam pouca profundidade teórica, sedimentando-se na esfera técnica.

Outro aspecto desenvolvido no trabalho diz respeito ao potencial formador da experiência como mecanismo de produção do saber docente. Nóvoa (1992, p. 26) assinala que: "[...], é importante a criação de redes de (auto)formação participada, que permitam compreender a globalidade do sujeito, assumindo a formação como um processo interactivo e dinâmico". Desse modo, a relação de troca entre professores no decorrer de suas vivências tende a preencher as lacunas, cuja formação inicial não poderia supor ou mesmo suprir.

O estudo concluiu que a formação do professor necessita romper com a lógica alienante que, por vezes, instrumentaliza a formação docente. O professor investe politicamente em suas práticas na busca por superar problemas sociais e educacionais; nesse sentido, o processo de formação não se limita às situações isoladas e desconectadas das suas vivências. 
Em continuidade aos trabalhos correlatos ao período de 2017, foi extraído da plataforma de pesquisa o artigo "Evolução do perfil didático-pedagógico do professor-engenheiro, de Molisani. O estudo foi realizado por meio de uma revisão bibliográfica, tendo por propósito analisar o processo de formação do engenheiro.

O perfil do professor-engenheiro elaborado promove um olhar sobre a docência no Ensino Superior, evidenciando que este docente deve ir além dos conhecimentos específicos. O desafio para o professor é fazer-se compreender, ser exitoso no processo de transposição didática (linguagem, práticas de sala de aula que se alinham ao perfil docente).

O autor aborda a uniformização do trabalho docente ao se referir à prática de ensino como limitada por práticas tradicionais, tendo por método aulas expositivas, exercícios laboratoriais e a avaliação do processo ensino/aprendizagem resumida a um teste único. Logo, as atividades de ensinar ou a exclusiva atuação como engenheiro acabam por se excluir, uma vez que o professor-engenheiro passa a atuar apenas sobre atividades de ensino, distanciando-se do seu conhecimento prático.

Conforme Isaia e Bolzan (2009, p.135), a docência é: “[...], uma conquista social, compartilhada, pois implica em trocas e representações. O processo de aprender a ser professor se dá no exercício continuado da docência". Assim, o professor-engenheiro e outros, de formação inicial similar, se introduzem no processo ensino/aprendizagem também como aprendizes, condição que o educador deve vivenciar permanentemente.

O trabalho ressalta que os docentes oriundos de carreiras cujo currículo não inclua o saber pedagógico necessitam ser incentivados a buscar cursos de formação docente quando atuantes em instituições de ensino. Por isso, ressalta-se que a figura do professor bacharel/tecnólogo, além da busca por assimilar os conhecimentos pedagógicos, quando na EPT, também necessita se familiarizar com seus fundamentos.

Quadro 7 - Publicações analisadas (2018)

\begin{tabular}{|c|c|c|c|c|c|}
\hline \multicolumn{2}{|l|}{2018} & \multicolumn{4}{|c|}{ Descritores } \\
\hline Artigos & Autores & $\begin{array}{c}\text { Identidade } \\
\text { docente }\end{array}$ & $\begin{array}{l}\text { Professor } \\
\text { Bacharel/ } \\
\text { Tecnólogo }\end{array}$ & $\begin{array}{c}\text { Docência } \\
\text { na EPT }\end{array}$ & $\begin{array}{c}\text { Formação } \\
\text { pedagógica }\end{array}$ \\
\hline $\begin{array}{l}\text { Mediação entre a escola e o } \\
\text { novo mundo do trabalho na } \\
\text { formação de técnicos de nível } \\
\text { médio }\end{array}$ & Souza & - & 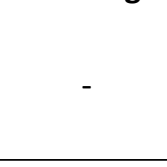 & $x$ & - \\
\hline $\begin{array}{l}\text { O trabalho docente nos } \\
\text { Institutos Federais no contexto } \\
\text { da Expansão da Educação } \\
\text { Superior }\end{array}$ & $\begin{array}{l}\text { Silva; } \\
\text { Melo }\end{array}$ & - & - & $x$ & - \\
\hline
\end{tabular}

Fonte: A autora.

No recorte temporal, ano de 2018, destacamos o estudo "Mediação entre a escola e o novo mundo do trabalho na formação de técnicos de nível médio", de Souza, que analisou a mediação entre a escola e o mundo do trabalho em um IF a partir da disciplina Estágio Supervisionado. 
A composição amostral relacionou os sujeitos (discentes, docentes, equipe gestora) que estivessem ligados direta/indiretamente às atividades do Estágio Supervisionado desenvolvidas no âmbito de cursos técnicos ofertados de modo integrado, concomitante ou subsequente ao Ensino Médio em cinco IFs. Durante a investigação foram aplicadas entrevistas semiestruturadas, questionários eletrônicos e o registro de grupos focais.

Como o objetivo de compreender os processos referentes ao Estágio Supervisionado na formação discente, foi necessário destacar as concepções e práticas docentes que orientaram o trabalho pedagógico. Assim, a preocupação com o Estágio Supervisionado decorre do propósito de avaliar como esta disciplina tem estado ou não alinhada aos fundamentos EPT. Refere-se à qualificação profissional indispensável para o ingresso e permanência do indivíduo no mundo do trabalho:

O que está posto para os Institutos Federais é a formação de cidadãos como agentes políticos capazes de ultrapassar obstáculos, pensar e agir em favor de transformações políticas, econômicas e sociais imprescindíveis para a construção de um outro mundo possível. A referência fundamental para a educação profissional e tecnológica é o homem e, por isso, o trabalho, como categoria estruturante do ser social é seu elemento constituinte (PACHECO, 2011, p. 22).

Outro aspecto suscitado pelo autor diz respeito à concepção de estágio como uma atividade meramente prática, de cunho certificatório. A análise dos dados coletados pelo estudo revela a ausência de compreensão dos sujeitos investigados quanto à função desse componente curricular na formação do aluno de cursos técnicos. Tanto que na percepção dos estudantes estagiar significa atividade prática monitorada, por meio da qual o discente adquire habilidades que o "capacitam" para várias chances de empregabilidade.

Por consequência, os dados destacaram uma supervalorização das atividades práticas (na figura do Estágio Supervisionado) como elemento mediador entre a escola e o mundo de trabalho. Ao considerar a realidade das instituições participantes do estudo, o autor concluiu que a prática do Estágio Supervisionado encontra-se distorcida, limitando o seu expressivo potencial pedagógico na formação de técnicos de nível médio.

A formação técnica de nível médio no espaço dos IFs advém de uma composição curricular que busca promover a educação de forma integral (teoria e prática relacionadas, um indivíduo crítico sobre sua realidade e capaz de transformá-la). Embora o estudo tenha concluído sobre a fragilidade da proposta de Estágio Supervisionado, evidenciou também que o professor é figura relevante por conduzir a modificação de tal quadro. Nesse sentido, foi observado que há um descompasso entre o perfil docente e a perspectiva de ensino prevista pelos Institutos Federais.

Em continuidade à análise, no ano de 2018 abordamos a pesquisa "O trabalho docente nos Institutos Federais no contexto de expansão da educação superior", de Silva e Melo. Trata do relato de estudo concluído em 2015, que apresentou o processo de reorganização da Rede Federal de Educação Profissional e Tecnológica no âmbito da ampliação da oferta da Educação Superior. Ainda salienta a influência deste movimento sobre o trabalho dos docentes dos cursos superiores dos Institutos Federais. 
A pesquisa possui caráter qualitativo, tendo sido adotados como instrumentos de coleta de dados a pesquisa documental, a observação e entrevistas. Primeiramente, os autores propõem discutir a expansão da oferta do Ensino Superior por intermédio dos IFs, refletindo como esse quadro se consolidou como política pública.

A investigação discute a ampliação da Educação Superior por meio do panorama representado pelo Instituto Federal do Norte de Minas Gerais (IFNMG). Segundo Silva e Melo (2018), os Institutos Federais, em sua nova formatação (a partir de 2008), meIhoraram sua infraestrutura, recursos humanos e condições materiais, e tal conjuntura viabilizou a verticalização do ensino.

A oferta expressiva de cursos superiores nos IFs, no entanto, evidenciou problemática relacionada à necessidade de formação pedagógica dos docentes na instituição. Moura (2008, p. 31) reflete acerca da relevância da formação para atuação como professor na EPT:

Esse é um problema estrutural do sistema educacional e da própria sociedade brasileira, pois, enquanto para exercer a Medicina ou qualquer outra profissão liberal é necessária a correspondente formação profissional, para exercer o Magistério, principalmente, o superior ou a denominada educação profissional, não há muito rigor na exigência de formação na correspondente profissão - a de professor.

O autor mencionado apresenta um quadro em que a formação docente não constitui premissa para o ato de ensinar, dessa forma corroborando as constatações do estudo em análise. Foram realizadas entrevistas com dez professores, gestores ligados à Reitoria e aos campi, pesquisadores, sindicalistas e indivíduos participantes da extensão sobre sua visão sobre o movimento de "ifetização".

A investigação evidenciou que na realidade do INFMG, a "ifetização" acarretou aos docentes o trabalho polivalente, decorrente das diversas funções que assumem. $\mathrm{Na}$ constância de atuarem no Ensino Superior, a sua atividade como professor intensificou-se, despendendo mais do tempo, das energias físicas e emocionais.

Tendo em vista a busca por analisar trabalhos que fundamentassem a discussão da docência na EPT, no marco temporal de 2013 a 2018, observamos a necessidade de acrescentar ao estudo os seguintes artigos: 
Quadro 8 - Seleção de artigos acerca da docência na EPT

\begin{tabular}{|c|c|c|c|c|}
\hline № & 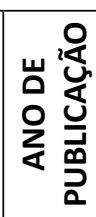 & TíTULO & 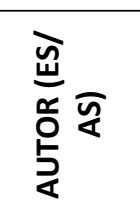 & SÍNTESE DO TRABALHO \\
\hline 1 & $\stackrel{m}{\stackrel{\sim}{\sim}}$ & $\begin{array}{l}\text { A Educação Profissional e } \\
\text { Tecnológica e a aprendizagem } \\
\text { da docência: o que está sendo } \\
\text { pesquisado nas produções } \\
\text { acadêmico-científicas? }\end{array}$ & 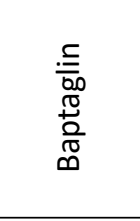 & $\begin{array}{l}\text { Apresenta um panorama de estudos que } \\
\text { discutem a aprendizagem da docência na } \\
\text { EPT. }\end{array}$ \\
\hline 2 & 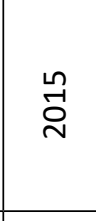 & $\begin{array}{l}\text { Formação de professores para a } \\
\text { Educação Profissional e Tecnológica } \\
\text { a distância da rede federal de } \\
\text { educação brasileira: análise das } \\
\text { produções acadêmicas }\end{array}$ & 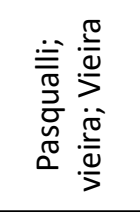 & $\begin{array}{l}\text { Realiza um levantamento das pesquisas } \\
\text { em nível stricto sensu acerca da formação } \\
\text { de professores para EPT a distância. }\end{array}$ \\
\hline 3 & & $\begin{array}{l}\text { A formação de professores para } \\
\text { a Educação Profissional e o Plano } \\
\text { Nacional de Educação (PNE): quais } \\
\text { as perspectivas? }\end{array}$ & 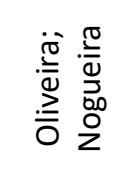 & $\begin{array}{l}\text { Relaciona as características da formação } \\
\text { de professores para a EPT e o Plano } \\
\text { Nacional de Educação (PNE). }\end{array}$ \\
\hline 4 & & $\begin{array}{l}\text { Licenciaturas nos Institutos Federais: } \\
\text { aspectos para discussão }\end{array}$ & 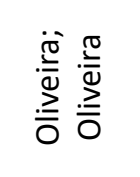 & $\begin{array}{l}\text { Trata das Licenciaturas ofertadas nos } \\
\text { Institutos Federais observando como é } \\
\text { articulado o conhecimento pedagógico e } \\
\text { técnico nesses cursos. }\end{array}$ \\
\hline 5 & $\stackrel{\infty}{\stackrel{\infty}{\sim}}$ & $\begin{array}{l}\text { Formação de professores da } \\
\text { Educação } \\
\text { Profissional: análise de produções } \\
\text { acadêmicas }\end{array}$ & $\stackrel{\frac{\pi}{2}}{\frac{.0}{2}}$ & $\begin{array}{l}\text { Reuniu produções científicas sobre a } \\
\text { formação de professores para EPT nas } \\
\text { reuniões dos principais eventos da área } \\
\text { de educação: ANPEd, ENDIPE, SENEPT } \\
\text { e Colóquio Nacional A Produção do } \\
\text { Conhecimento em Educação Profissional. }\end{array}$ \\
\hline 6 & & $\begin{array}{l}\text { A formação de professores da } \\
\text { Educação Profissional como objeto } \\
\text { de estudo dos Programas de Pós- } \\
\text { Graduação no Brasil }\end{array}$ & 离 & $\begin{array}{l}\text { Analisa, no período de } 2010 \text { a 2017, } \\
\text { trabalhos sobre a formação de } \\
\text { professores para EPT nos Programas de } \\
\text { Pós-Graduação. }\end{array}$ \\
\hline
\end{tabular}

Fonte: A autora.

Em 2013 o artigo "A Educação Profissional e Tecnológica e a aprendizagem da docência: o que está sendo pesquisado nas produções acadêmico-científicas?", de Baptaglin, buscou reunir trabalhos que refletissem sobre a aprendizagem da docência na EPT, sobretudo, nos cursos de Ensino Médio Integrado.

Foram consultados a Rede Sulbrasileira de Investigadores da Educação Superior (Ries) (2007 e 2008); Revista Brasileira de Educação Profissional e Tecnológica em suas três edições (2008, 2009 e 2010), o site da Secretaria de Educação Profissional e Tecnológica (Setec), Revista Brasileira de Educação - Anped (1995-2009) e o Portal de dissertações e teses da Capes. Nesse sentido, a autora buscou conhecer o panorama das produções científicas no tocante ao professor da EPT.

Tanto na Ries quanto na Revista da Anped a aprendizagem da docência é estudada amplamente, tendo sido tratado como aspecto inerente o processo de formação do professor, inclusive suas narrativas. Sobre as narrativas Isaia e Bolzan (2009, p. 127) 
comentam que: “(...) partir das narrativas permite a compreensão de como os professores experimentam o mundo da docência e a reconstroem pelos fios da memória (...)". A complexidade da docência demanda ir além dos métodos e da realidade de sala de aula, mas conhecer o professor por inteiro (pessoal, profissional, etc.).

As discussões apontadas pela Setec e a Revista Brasileira de Educação Profissional e Tecnológica apontam que a expansão dos IFs, intensificou a necessidade de qualificar o quadro de professores. As formações ou cursos de Pós-Graduação com esse objetivo ainda eram iniciativas limitadas, sendo sugerida a criação de Licenciaturas para Educação Profissional e Tecnológica, dado o elevado número de professores atuantes na EPT sem formação pedagógica.

No portal da Capes os trabalhos analisados situaram a questão em torno da adaptação dos cursos e propostas de formação aos diversos contextos de atuação dos professores, tendo em vista a singularidade dos saberes que cada um mobiliza no seu ambiente de atuação. Como forma de romper com uma cultura de formação de professores descontínua, a autora entende como imprescindível torná-la uma política pública permanente.

No ano de 2015 destacamos o artigo "Formação de professores para a Educação Profissional e Tecnológica a distância da rede federal de educação brasileira: análise das produções acadêmicas", de Pasqualli, Vieira e Vieira. Ao verificar os estudos que tratam da formação de professores para EPT, em cursos a distância, na Rede Federal de Educação Brasileira constataram a limitada produção sobre a temática em reuniões científicas.

A pesquisa realizada teve cunho documental e avaliou, entre 2009 e 2014, artigos advindos do (a): Banco de teses e dissertações da Capes - Coordenação de Aperfeiçoamento de Pessoal de Nível Superior; Biblioteca Digital Brasileira de Teses e Dissertações - BDTD, do Instituto Brasileiro de Informação em Ciência e Tecnologia - Ibict; Trabalhos apresentados no Senept - Seminário Nacional de Educação Profissional e Tecnológica; Reuniões da Anped (32a a 36ạ) - Associação Nacional de Pós-Graduação e Pesquisa em Educação; Endipe - Encontro Nacional de Didática e Prática de Ensino; Educere - Congresso Nacional de Educação (PUC - PR); Eventos da Abed - Associação Brasileira de Educação a Distância e o Colóquio Nacional Educação Profissional do IFRN - Instituto Federal de Educação, Ciência e Tecnologia do Rio Grande do Norte.

Os autores destacam a ausência de trabalhos acerca da formação docente na EPT como um silêncio com variados significados. Entre eles, a criação dos IFs, no marco temporal considerado ainda ser recente; a natureza do Ensino Técnico que exige professores de formação em Bacharelado e que não possuem em seus currículos a formação pedagógica. Além disso, evidenciaram uma relação de oposição entre o professor profissional da educação versus o professor da área técnica, este último atuante na EPT.

O equilíbrio entre a formação técnica e a docência é discutido por Moura (2008, p. 31), que afirma: "É fundamental que se busque uma melhor formação profissional desses docentes tanto na perspectiva dos conhecimentos específicos da área profissional em que atuam como no que se refere à formação didático-político-pedagógica". 0 autor propõe que o processo de formação contemple a qualificação docente a partir da relação harmônica entre conhecimento técnico e pedagógico. 
No recorte temporal de 2016 o trabalho "A formação de professores para a Educação Profissional e o Plano Nacional de Educação (PNE): quais as perspectivas?", de Oliveira e Nogueira, sintetiza por meio de documentos legais, principalmente no comentário das metas do Plano Nacional de Educação (PNE) as tendências da formação de professores para EPT (intitulada como Forprofep). Desse modo, propõe rever a condição atual e perspectivas de discussão da docência nesse espaço.

As normativas legais estudadas buscam funcionar em uma relação de complementaridade com o PNE (2014-2024), tendo em vista que este recomenda que os professores da Educação Básica possuam o curso de Licenciatura na sua área de atuação. Segundo Oliveira e Nogueira (2016, p. 154): //“Há também falta de estudos sobre a denominada epistemologia das áreas técnicas que subsidie a construção de projetos político-pedagógicos para a formação dos seus professores". Nesse sentido, a Forprofep tornou-se vulnerável por incluir processos de formação historicamente comprovados como iniciativas aceleradas e superficiais tanto no tocante à formação inicial como continuada.

Assim, o estudo descreve como quadros possíveis à estruturação de projetos de Forprofep a divisão da formação pedagógica em relação à formação específica, em uma aparente relação de interdependência. Em outro quadro, a Forprofep se realizaria por cursos de Licenciatura, nos quais a formação pedagógica seria como uma segunda Licenciatura para graduados, com carga horária e currículo definidos para tal.

Ainda em 2016, o estudo "Licenciaturas nos Institutos Federais: aspectos para discussão", de Oliveira e Oliveira, analisa o processo de formação dos professores nesses cursos, com vistas ao exercício da docência no Ensino Médio Integrado dos IFs. Dessa forma, foram analisados seis projetos político-pedagógicos diferentes de cursos de Licenciatura em Ciências Biológicas em três Institutos Federais mineiros. Foi constatado, a partir da análise destes documentos, que os IFs procuram atender à necessidade de formação docente para EPT e, consequentemente, para o Ensino Médio Integrado.

Segundo Oliveira e Oliveira (2016, p. 27): //"não basta ao professor de biologia, matemática, física, português, etc., dominar os conhecimentos relativos a essas áreas do conhecimento". A organização de cursos de formação de professores para EPT demanda uma preocupação com elementos como carga horária, matriz curricular e a conciliação entre conhecimento específico e pedagógico.

Nessa perspectiva, os Institutos Federais representam o ensino voltado para o mundo do trabalho, o que torna esse espaço singular. Nesse sentido, Moura (2008, p. 28) afirma: "Refere-se, assim, ao poder da EPT de contribuir com o aumento da capacidade de (re)inserção social, laboral e política dos seus formandos (...)". A docência com vistas ao contexto da EPT potencializa os efeitos da educação, pois superamos a condição de recomendação legal e passamos a valorizar o professor e a modalidade educacional em que atua.

No recorte temporal de 2018 salientamos o artigo "Formação de professores da Educação Profissional: análise de produções acadêmicas", de Vieira. O estudo apresentou o estado do conhecimento a respeito da formação de professores para EPT no pe- 
ríodo de 2010 a 2017. Foram analisadas produções científicas resultantes das reuniões de eventos como: Anped, Endipe, Senept e Colóquio Nacional A Produção do Conhecimento em Educação Profissional.

Foi realizada uma pesquisa qualitativa, tendo o material reunido sendo explorado à luz da análise de conteúdo. Caracterizou-se por ser uma investigação de cunho bibliográfico e de campo, com a aplicação de entrevistas com professores da EPT. Como forma de situar a discussão, os trabalhos foram organizados por temáticas: processo de constituição da docência/saberes docentes na EP (Educação Profissional), análise das políticas de formação de professores para a EP, análise de programas ou cursos de formação de professores para a EP, formação e trabalho docente.

Entre as categorias realçadas pelo estudo, "o processo de constituição da docência/saberes docentes na EP" oportunizou a reflexão em torno das práticas pedagógicas vivenciadas pelo professor na EPT, sobretudo bacharéis/tecnólogos. Assim, a sobreposição do conhecimento técnico da formação inicial sobre o docente ainda é uma problemática para a formação docente do não licenciado. Na temática "os programas ou cursos de formação de professores para a EP" foi evidenciado que as políticas de formação docente para EPT seguem reativas ou emergenciais às situações que o cotidiano escolar e institucional apresentar.

Por fim, Vieira (2018, p. 257) conclui que: //“No tocante aos conteúdos abordados nos trabalhos, boa parte centraliza-se na constituição da professoralidade, enfocando os saberes docentes e a constituição da identidade de professor". Refere-se aos aspectos inerentes à formação do professor, inclusive para EPT, referendando os estudos que discutem a docência como processo.

Por último, também em 2018, destacamos o trabalho "A formação de professores da Educação Profissional como objeto de estudo dos Programas de Pós-Graduação no Brasil", de Vieira, Vieira e Araújo. Trata-se de uma pesquisa meta-analítica (Estado do Conhecimento) que explorou teses e dissertações de Pós-Graduação no período de 2010 a 2017 sobre formação de professores para a Educação Profissional, no site da Capes, dos Programas de Pós-Graduação e da Biblioteca Digital Brasileira de Teses e Dissertações do Instituto Brasileiro de Informação em Ciência e Tecnologia (Ibict).

A investigação caracteriza-se por ser de cunho bibliográfico e documental, constituída por 56 trabalhos. A análise de dados fundamenta-se na teoria de análise de conteúdo, dessa forma definindo três categorias de discussão: características gerais da produção, temáticas investigadas e referencial teórico e percurso metodológico.

A exemplo do trabalho anterior, este evidencia, por meio da divisão por temáticas, as produções científicas. Com esse propósito os autores constatam um número maior de trabalhos dedicados à constituição da docência e dos seus saberes, e de modo secundário apresenta uma nova expressão temática "o professor da EP: razões do ingresso na docência, perfil, identidade e trajetória". Observamos a necessidade de pesquisas no que se refere às vivências e trajetórias como professor na EPT, sendo tais vivências fundamentais para formatar e propor cursos de formação e qualificação da atividade docente. 
Outro aspecto explorado diz respeito à identidade do professor como um relevante aspecto do seu processo de formação, de modo que Isaia e Bolzan (2009, p. 136) enfatizam: “(...) tornar-se docente exige um permanente processo de aprendizagem que acompanha toda a trajetória do professor, indicando sua incompletude como ser humano e como docente". Assim, a EPT suscita a preocupação com o seu professor quando propõe os cursos de formação não apenas por uma exigência legal, mas quando promove o equilíbrio entre os saberes, trajetórias docentes e as demandas sociais que atende.

\section{CONSIDERAÇÕES FINAIS}

A formação docente para EPT apresenta-se como um campo que demanda maior dedicação dos estudos acadêmicos, sobretudo no que diz respeito aos professores bacharéis/tecnólogos que atuam maciçamente nesse espaço. Desse modo, nosso trabalho procurou reunir artigos que analisassem a identidade docente dos professores sem formação pedagógica, no entanto a discussão ainda necessita de maior aprofundamento, uma vez que os trabalhos existentes discutem de um modo geral a docência para EPT.

No inventário realizado no site SciELO, encontramos nove artigos que apresentaram visões diversificadas acerca da problemática levanta para estudo, a docência dos bacharéis/tecnólogos na EPT. Nessa perspectiva, foi possível compreender que a formação para professores não licenciados ainda é resultado de iniciativas pontuais e limitadas a situações específicas do cotidiano escolar.

Como forma de aprofundar a questão inserimos no estudo seis artigos, cujos autores trabalham intensamente a temática da docência para EPT, a figura do bacharel nesse espaço, a aprendizagem docente, a constituição de saberes do professor, assim como os processos que participam da constituição da sua(s) identidade(s) docente(s). Podemos concluir que nesse contexto há a polarização entre o conhecimento técnico e o conhecimento pedagógico do professor atuante na EPT, tendo em vista que os cursos de formação inicial ou mesmo continuada apresentam ainda dificuldade em conciliar tais aspectos em suas políticas de formação.

Refletir sobre as trajetórias e vivências docentes na EPT, portanto, promove o entendimento acerca das particularidades dessa modalidade educacional, principalmente quando se refere à qualificação do trabalho dos professores. Por fim, entendemos que a identidade docente é um aspecto singular da formação, por isso necessita estar refletida no percurso formativo dos indivíduos, tanto por eles como pelas instituições em que atuam.

\section{REFERÊNCIAS}

BAPTAGLIN, L. A. A Educação Profissional e Tecnológica e a aprendizagem da docência: o que está sendo pesquisado nas produções acadêmico-científicas? In: Congresso Nacional de Educação - EDUCERE. 11., 2013, Curitiba, 2013. Anais [...]. Curitiba: Pontifícia Universidade Católica do Paraná. 2013. p. 7.709-7.725. Disponível em: https://educere.bruc.com.br/CD2013/pdf/7518_4366.pdf. Acesso em: 10 abr. 2020.

BARDIN, L. Análise de conteúdo. Tradução Luís Antero Reto e Augusto Pinheiro. Lisboa: Edições 70, 1977. BASTOS, C. C. B. C.; ROVARIS, N. A. Z. A relevância do processo de autoavaliação institucional da Universidade Tecnológica para a configuração do bom professor. Avaliação, Campinas, v. 21, n. 3, p. 767-781, nov. 2016. Disponível em: http://www.scielo.br/pdf/aval/v21n3/1982-5765-aval-21-03-00767.pdf. Acesso em: 5 out. 2018. 
BRASIL. Lei no 9.394, de 20 de dezembro de 1996. Estabelece as diretrizes e bases da educação nacional. Diário Oficial da União: seção 1, Brasília, DF, p. 27.833, 23 dez. 1996. PL 1258/1988. Disponível em: http://www.planalto.gov.br/ccivil_03/Leis/L9394.htm. Acesso em: 20 out. 2018.

BRASIL. Lei no 11.892, de 29 de dezembro de 2008. Institui a Rede Federal de Educação Profissional, Científica e Tecnológica, cria os Institutos Federais de Educação, Ciência e Tecnologia, e dá outras providências. Diário Oficial da União: seção 1, Brasília, DF, p. 1, 30 dez. 2008. PL 3775/2008. Disponível em: http:// www.planalto.gov.br/ccivil_03/_Ato2007-2010/2008/Lei/L11892.htm. Acesso em: 20 out. 2018.

BRASIL. Rede Federal de Educação Profissional, Científica e Tecnológica. Histórico. Brasília, 11 abr. 2016. Disponível em: http://redefederal.mec.gov.br/historico. Acesso em: 4 nov. 2018.

CANDAU, V. M. F. Ser professor/a hoje: novos confrontos entre saberes, culturas e práticas. Educação, Porto Alegre, v. 37, n. 1, p. 33-41, jan./abr. 2014. Disponível em: http://revistaseletronicas.pucrs.br/ojs/ index.php/faced/article/view/15003/10923. Acesso em: 12 jul. 2019.

CARVALHO, O. F.; SOUZA, F. H. M. Formação do docente da Educação Profissional e Tecnológica no Brasil: um diálogo com as faculdades de Educação e o curso de Pedagogia. Educação \& Sociedade, Campinas, v. 35, n. 128, p. 883-908, jul./set. 2014. Disponível em: http://www.scielo.br/pdf/es/v35n128/0101-7330es-35-128-00883.pdf. Acesso em: 5 out. 2018.

CUNHA, Maria Isabel da. O bom professor e sua prática. Campinas: Papirus, 1992.

FARTES, V. L. B. A cultura profissional dos grupos de pesquisa nos Institutos Federais: uma comunidade de práticas? Cadernos de Pesquisa, v. 44, n. 154, p. 850-874, out./dez. 2014. Disponível em: http://www. scielo.br/pdf/cp/v44n154/1980-5314-cp-44-154-00850.pdf. Acesso em: 5 out. 2018.

FRIGOTTO, G.; CIAVATTA, M.; RAMOS, M. Diretrizes Curriculares Nacionais para a Educação Profissional Técnica de nível médio em debate. In: PACHECO, E. (org.). Perspectivas da Educação Profissional Técnica de nível médio: proposta de Diretrizes Curriculares Nacionais. São Paulo: Moderna, 2012. p. 8-16.

GATTI, B. A. Pesquisar em educação: considerações sobre alguns pontos-chave. Diálogo Educacional, Curitiba, v. 6, n. 19, p. 25-35, set./dez. 2006. Disponível em: https://periodicos.pucpr.br/index.php/dialogoeducacional/article/view/24177/22873. Acesso em: 12 dez. 2018.

GATTI, B. A. et al. (org.). Professores no Brasil: novos cenários de formação. Brasília: Unesco, 2019.

GIOVINAZZO JÚNIOR, C. A. A formação profissional nos cursos de licenciatura e o exercício do magistério na educação básica: intenções, realizações e ambiguidades. Educar em Revista, Curitiba, n. esp.1, p. 5168, jun. 2017. Disponível em: http://www.scielo.br/pdf/er/nspe.1/0104-4060-er-01-00051.pdf. Acesso em: 5 out. 2018.

HALL, S. A identidade cultural na pós-modernidade. Tradução Tomaz Tadeu da Silva e Guacira Lopes Louro. 11. ed. Rio de Janeiro: DP\&A, 2006.

ISAIA, S. M. A.; BOLZAN, D. P. V. Trajetórias da docência: articulando estudos sobre os processos formativos e a aprendizagem de ser professor. In: ISAIA, S. M. A.; BOLZAN, D. P. V. (org.). Pedagogia universitária e desenvolvimento profissional docente. Porto Alegre: Edipucrs, 2009. p. 121-143.

JOSSO, M.-C. Experiência de vida e formação. Tradução José Claudino e Júlia Ferreira. São Paulo: Cortez, 2004.

MOLISANI, A. L. Evolução do perfil didático-pedagógico do professor-engenheiro. Educação e Pesquisa, São Paulo, v. 43, n. 2, p. 467-482, abr./jun. 2017. Disponível em: http://www.scielo.br/pdf/ep/v43n2/ 1517-9702-ep-S1517-9702201608149237.pdf. Acesso em: 5 out. 2018.

MOROSINI, M. C.; FERNANDES, C. M. B. Estado do conhecimento: conceitos, finalidades e interlocuções. Educação Por Escrito, Porto Alegre, v. 5, n. 2, p. 154-164, jul./dez. 2014. Disponível em: http://revistaseletronicas.pucrs.br/ojs/index.php/porescrito/article/view/18875. Acesso em: 18 fev. 2020.

MOURA, D. H. A formação de docentes para a educação profissional e tecnológica. Revista Brasileira da Educação Profissional e Tecnológica, Natal, v. 1, n. 1, p. 23-38, 2008. Disponível em: http://www2.ifrn. edu.br/ojs/index.php/RBEPT/article/view/2863/1004. Acesso em: 2 jul. 2019.

NÓVOA, A. Formação de professores e profissão docente. In: NÓVOA, A. (org.). Os professores e a sua formação. Lisboa: Publicações Dom Quixote, 1992. p. 15-34.

OLIVEIRA, V. F. O grupo como dispositivo de formação: conhecendo trajetos na educação superior. In: ISAIA, S. M. A.; BOLZAN, D. P. V. (org.). Pedagogia universitária e desenvolvimento profissional docente. Porto Alegre: Edipucrs, 2009. p. 102-120.

OLIVEIRA, M. R. N. S.; NOGUEIRA, C. G. A formação de professores para a Educação Profissional e o Plano Nacional de Educação (PNE): Quais as perspectivas? Holos, Natal, v. 6, n. 32, p. 145-155. ago./set. 2016. Disponível em: http://www2.ifrn.edu.br/ojs/index.php/HOLOS/article/view/4987. Acesso em: 2 abr. 2020. 
OLIVEIRA, B. M.; OLIVEIRA, M. R. N. S. Licenciaturas nos institutos federais: aspectos para discussão. Revista Brasileira de Educação Profissional Tecnológica, Natal, v. 1, n. 10, p. 22-33. out./dez. 2015. Disponível em: http://www2.ifrn.edu.br/ojs/index.php/RBEPT/article/view/3493/1473. Acesso em: 2 abr. 2020.

PACHECO, E. Institutos federais: uma revolução na educação profissional e tecnológica. Natal: IFRN, 2011. PASQUALLI, R.; VIEIRA, J. L.; VIEIRA, M. M. M. Formação de professores para a Educação Profissional e Tecnológica a distância da rede federal de educação brasileira: análise das produções acadêmicas. Revista Brasileira de Educação Profissional Tecnológica, Natal, v. 2, n. 9, p. 22-31. out./dez. 2015. Disponível em: http://www2.ifrn.edu.br/ojs/index.php/RBEPT/article/view/3558/1261. Acesso em: 2 abr. 2020.

RIBEIRO, G.; PIRES, D. E. P.; FLÔR, R. C. Concepção de biossegurança de docentes do ensino técnico de enfermagem em um estado do sul do Brasil. Trabalho, Educação e Saúde, Rio de Janeiro, v. 13, n. 3, p. 721-737, set./dez. 2015. Disponível em: http://www.scielo.br/pdf/tes/v13n3/1981-7746-tes-13-03-0721. pdf. Acesso em: 5 out. 2018.

ROLDÃO, M. C. Função docente: natureza e construção do conhecimento profissional. Revista Brasileira de Educação, Rio de Janeiro, v. 12, n. 34, p. 94-103, jan./abr. 2007. Disponível em: http://www.scielo.br/ pdf/rbedu/v12n34/a08v1234.pdf. Acesso em: 20 jun. 2019.

SILVA, P. F.; MELO, S. D. G. O trabalho docente nos Institutos Federais no contexto de expansão da educação superior. Educação e Pesquisa, São Paulo, v. 44, ago. 2018. Disponível em: http://www.scielo.br/pdf/ ep/v44/1517-9702-ep-44-e177066.pdf. Acesso em: 5 out. 2018.

SOUZA, F. C. S. Percurso formativo de engenheiros professores da educação profissional e tecnológica. Revista Brasileira de Estudos Pedagógicos, Brasília, v. 98, n. 248, p. 62-76, jan./abr. 2017. Disponível em: http://www.scielo.br/pdf/rbeped/v98n248/2176-6681-rbeped-98-248-00062.pdf. Acesso em: 5 out. 2018.

SOUZA, J. S. Mediação entre a escola e o novo mundo do trabalho na formação de técnicos de nível médio. Trabalho, Educação e Saúde, Rio de Janeiro, v. 16, n. 1, p. 123-140, jan./abr. 2018. Disponível em: http://www.scielo.br/pdf/tes/v16n1/1678-1007-tes-16-01-0123.pdf. Acesso em: 15 nov. 2018.

VIEIRA, M. M. M. Formação de professores da Educação Profissional: análise de produções acadêmicas. Holos, Natal, v. 2, n. 34. p. 243-258. Maio 2015/fev. 2018. Disponível em: http://www2.ifrn.edu.br/ojs/ index.php/HOLOS/article/view/3160. Acesso em: 3 abr. 2020.

VIEIRA, M. M. M.; VIEIRA, J. A.; ARAÚJO, M. C. P. A formação de professores da Educação Profissional como objeto de estudo dos Programas de Pós-Graduação no Brasil. Revista Educação em Questão, Natal, v. 56, n. 49. p. 139-167. jul./set. 2018. Disponível em: https://periodicos.ufrn.br/educacaoemquestao/ article/view/14320. Acesso em: 3 abr. 2020. 